\title{
CIUDADANÍA INFANTIL Y PARTICIPACIÓN EDUCATIVA EN EL PERÚ. ESTUDIO DE LA POBLACIÓN ESCOLAR DEL 5TO Y 6TO GRADO DEL NIVEL DE EDUCACIÓN PRIMARIA EN LOS DEPARTAMENTOS DE SAN MARTÍN, CAJAMARCA E ICA*.
}

\author{
CHILD CITIZENSHIP AND EDUCATIONAL PARTICIPATION \\ IN PERU. STUDY OF THE SCHOOL POPULATION, 5TH \\ AND 6TH GRADE OF PRIMARY EDUCATION LEVEL IN THE \\ DEPARTMENTS OF SAN MARTIN, CAJAMARCA AND ICA
}

Jerjes Loayza ${ }^{* *}$

\section{Resumen:}

Se plantea explorar el carácter participativo de la población escolar del 5to y 6to grado de primaria en el proceso del servicio de raciones y productos del Programa Nacional de Alimentación Escolar del Perú del nivel de educación primaria en los departamentos de San Martín, Cajamarca e Ica. Mediante la aplicación de grupos de discusión y entrevistas semi estructuradas, se identifican situaciones adversas de conflictos entre estudiantes que provocarán proceso de violencia simbólica y física desdibujando posibles procesos democráticos de participación ciudadana. Asimismo, se reconocen brechas de género entre las niñas y los niños lo cual reforzará la existencia de estructuras de inhibición participativa femenina patriarcales.

Palabras clave: participación, infancia, educación, ciudadanía, democracia.

\section{Abstract:}

It is proposed to explore the participatory nature of the school population of the 5th and 6 th grade of primary education in the process of serving rations and products of the National School Food Program of Peru of the level of primary education in the departments of San Martin, Cajamarca and Ica. Through the application of discussion groups and semi-structured interviews, adverse situations of conflict between students are identified that will cause a process of symbolic and physical violence blurring possible democratic processes of citizen participation. Gender

Investigación realizada como parte del proyecto con financiamiento “Educación, democracia y Nación en el Perú en el siglo XX y XXI", con código E1815150, avalado durante el año 2018 por el Vicerrectorado de Investigación y Posgrado de la Universidad Nacional Mayor de San Marcos. Dicho proyecto se encuentra en el marco del grupo de investigación

"Estado, Nación y Democracia en el Perú y América Latina".

** Docente investigador de la Universidad Nacional Mayor de San Marcos. Correo electrónico: mloayzaj@unmsm.edu.pe 
gaps are also recognized between girls and boys, which will reinforce the existence of participatory patriarchal female inhibition structures.

Keywords: participation, childhood, education, citizenship, democracy.

\section{INTRODUCCIÓN}

Los vínculos de tutelaje, aquella fórmula que inhibe a la ciudadanía en favor de determinadas esferas de dominación (Nugent, 2011), por parte de la familia y el orden instituido de la sociedad hacia los niños amilana la construcción del yo en detrimento de capacidades de interacción deliberativa entre niños, y entre niños y adultos. El rol que puedan tener, más allá de sus percepciones, en un ejercicio legítimo de sus derechos y deberes ciudadanos al momento de participar como tales, horadando en el sentido común establecido de la tutela hacia ellos y ellas, así como de la incapacidad que pueden representar en su entera magnitud. Vale acortar y rebasar la arbitrariedad del concepto general de participación, para enrumbar hacia la categoría de "protagonismo infantil", de modo que se pueda ahondar en su riqueza práctica y teórica, y no limitarla a concepciones ajenas al mundo escolar infantil. Bajo este rótulo, el artículo busca identificar las dificultades que impiden la participación en la gestión del servicio alimentario de los escolares del 5to y 6to grado del nivel de educación primaria en los departamentos de San Martín, Cajamarca e Ica. Se propugnan repercusiones en los sistemas democráticos, constituyendo una nueva matriz para el logro de una auténtica cultura democrática, de la que las y los niños sean actores calificados. Se rebasan, así, racionalidades adultocéntricas, las que, creyéndose dueña natural dela infancia, construyen estados de vulnerabilidad aún más agudos al anular todo tipo de incursión participativa infantil (Cussiánovich y Bazán, 2009). En este contexto, cabe no sólo considerar la opinión de los protagonistas del programa: es de gran importancia clasificar su participación al momento de la entrega y consumo.

Se trata de una investigación de tipo inductiva, debido a la inexistencia de antecedentes en torno al problema propuesto en el Perú. Es así que se utilizará literatura fenomenológica en el marco de considerar las entrevistas como un modo de percibir el pensamiento del otro. Asimismo, se utilizarán formas de analizar los discursos a través del diálogo en los grupos de discusión. En líneas generales nos lleva a enmarcarnos en una teoría de tipo fundamentada o "Grounded theory" estableciendo las categorías de nuestro estudio de acuerdo a los resultados encontrados. 


\section{MARCO METODOLÓGICO}

La investigación planteada es de tipo cualitativa teniendo como finalidad explorar la participación de los niños y niñas en el contexto de interacción social escolar. Se realizó una muestra por cuotas, dado que representará que cada departamento seleccionado busca ser representativo dada la selección por región natural, tanto la costa, la sierra y la selva. Al interior de cada región se planteó una muestra probabilística o aleatoria debido a que la población en cada zona natural es muy grande. Para ello se reconocieron dos segmentos importantes ${ }^{30}$ : dos instituciones educativas que cuenten con el servicio de raciones, es decir, desayunos ya preparados, y dos instituciones educativas que cuenten con el servicio de productos, es decir, desayunos para preparar.

Se eligieron dos instituciones educativas pertenecientes a la zona rural en donde se entregan productos para su preparación en desayunos, y dos instituciones educativas pertenecientes a la zona urbana, en donde se entregan raciones listas para ser consumidas directamente. Es así como se establecen las siguientes provincias y distritos:

\section{Sierra norte: Cajamarca}

Zona rural: Distrito de Bambamarca, provincia de Hualgayoc.

Zona urbana: Distrito De Jesús, provincia de Cajamarca.

\section{Amazonía Alta: San Martín}

Zona urbana: Distrito de Tarapoto, provincia de San Martín.

Zona rural: Distrito de San José de Sisa, provincia de El Dorado.

\section{Costa Central: Ica:}

Zona urbana: Distrito de Ocucaje, provincia de Ica.

Zona rural: Distrito de Huancano, provincia de Palpa.

La investigación se desarrolló entre los meses de julio y diciembre del año 2018. Las técnicas utilizadas para el proceso de recolección de datos fueron dos: Por un lado, la entrevista semi estructurada, en donde se buscó ahondar en las significaciones del escolar, de manera que exprese libremente sus motivaciones, creencias, sentimientos, estilos de pensamiento, imaginarios y concepciones. Son un total de 24 entrevistas, de una duración no mayor a 20 minutos cada una. Por otro lado, se aplicó el grupo de discusión, en donde se aplicó un grupo de discusión por cada colegio de una duración no mayor de 30 minutos. Los nombres utilizados serán seudónimos, para proteger la identidad de los menores de edad participantes.

30 Los segmentos se establecen en función de características importantes por su interés específico descriptivo y sobre todo porque, si se desea extrapolar a toda la población, pueden tener que ver con la variable dependiente (Morales, 2012). 
Debido a la amplitud del universo de estudio, basándose en más de 5000 colegios a lo largo de todo el país se utilizaron instrumentos cualitativos. $\mathrm{Al}$ no existir investigaciones previas en el campo de las percepciones de los escolares, ni en torno a su participación en los diferentes espacios de las IIEE, en relación a la Alimentación Escolar en el Perú, en el marco del cumplimiento de funciones de Qali Warma, apelamos a un nivel enteramente exploratorio. A modo de resumen de las actividades realizadas para la recolección de los datos objeto de análisis, se efectuaron un total de 76 entrevistas individuales, 12 grupos de discusión, teniendo un total de 88 unidades objeto de sistematización y análisis, incluyendo los grupos de discusión.

\section{TABLA RESUMEN DE TRABAJO DE CAMPO}

\begin{tabular}{|c|c|c|c|}
\hline Unidad Territorial & Entrevistas Individuales & Grupos Focales & Total \\
\hline Cajamarca & 26 & 4 & 30 \\
\hline San Martín & 25 & 4 & 29 \\
\hline Ica & 25 & 4 & 29 \\
\hline Total & 76 & 12 & 88 \\
\hline
\end{tabular}

\section{MARCO TEÓRICO}

La estructura básica del sistema educativo peruano ha logrado estabilizarse a lo largo de los últimos 110 años, siendo la expansión de la obligatoriedad un cambio muy importante, debido a lo cual ha necesitado de recursos crecientes, teniendo una oportunidad para repensar la prestación de servicios educativos (Guadalupe, León, Rodríguez y Vargas, 2017). Cabe destacar que Stojnic y Carrillo (2016, p.214) plantean que en Latinoamérica a mayor cantidad de años de educación, así como un mayor índice de calidad educativa, se incidiría en una "mayor disposición de los jóvenes para reconocer la democracia como valiosa y a otros grupos como sujetos de derecho". Ello dependerá directamente de una educación de mayor calidad. No se puede olvidar que la educación es "indispensable en el proceso de poder garantizar la fidelidad de los ciudadanos hacia instituciones democráticas" (Stojnic y Carrillo, 2016. p. 198).

En este contexto, la situación de los docentes ha mejorado por un lado. Según demuestran investigaciones cuantitativas recientes (Carrillo, 2017) los docentes encuestados en el año 2014 mejoraron sus inquietudes con respecto a los docentes del año 2001. Carrillo establece que las actitudes hacia la vocación y la remuneración son mejores que hace trece años. Más aún, las actitudes sobre las relaciones interpersonales (con alumnos y colegas) se incrementaron 
(Carrillo, 2017). Sin embargo, para Cuenca (2012) hay otros problemas a considerar para la legitimidad de la docencia. En ese sentido, mejorar esta situación radica en hacer algo más que subir el salario a los docentes, ya que ello resulta únicamente un paliativo: urge revalorar el trabajo docente, el fortalecimiento de las competencias, técnicas docentes y el reconocimiento de su responsabilidad social. No se consigue nada con culpabilizarlos porque solo ocasiona la "victimización del magisterio" (Cuenca, 2012, p. 34).

Por su parte, en el ámbito de la vida doméstica como parte del contexto del escolar, el vacío producido por la inacción familiar en cierto momento crucial del desarrollo del adolescente, según demuestran la reciente investigación cualitativa de Demarini (2017), dado que en la transición de primaria a secundaria los estudiantes negativamente se ven afectados en diversos aspectos: pierden el apoyo de los adultos, el nivel de coordinación entre la casa y la escuela disminuye lo que ocasiona que el alumno tome decisiones perjudiciales para su desarrollo.

En dicho sentido, cabe resaltar la importancia de los aspectos emocionales de los jóvenes estudiantes, en tanto que permiten que valores cívicos democráticos se estructuren en el aspecto crítico de la comunidad estudiantil. Por ello, recurriremos a una breve exploración de las investigaciones cualitativas que ahondan dicho espectro. En este contexto investigué las relaciones interpersonales entre docentes, auxiliares y estudiantes en la comunidad autogestionaria de Huaycán teniendo como resultado la violencia carismática acaecida sobre los propios estudiantes. Estos aceptaban y legitimaban este ejercicio en la medida que venía acompañado de bromas y sarcasmo. Asimismo, se concluyó que la reproducción de la violencia estudiantil encuentra caldo de cultivo favorable en la inacción docente y en la propia violencia de los auxiliares hacia los estudiantes varones. Estos reaccionarían con ejercicios sexuales abusivos con sus propias compañeras (Loayza, 2011).

Cabe destacar también otro gran problema desde una perspectiva institucional: según refiere Magde (2017) el Estado peruano representa una grave contradicción al poner en tensión, por un lado, la propuesta de valores democráticos que garantizan que proyectos individuales se realicen $y$, por otro lado, los valores comunitarios particulares que se analizan en el contexto de Ayacucho en donde se tiene como objetivo el mantenimiento de la tradición. En efecto, es necesario y fundamental contar con nuevos marcos de referencia que reconozcan que no siempre la calidad debe ser utilitarista y que las oportunidades operan en un contexto imperfecto (Cuenca, 2015). A ello se suma la triada racial-social-económico que resalta las formas de discriminación en la escuela que, según sostiene Jacinto (2017), implica una 
evasión al problema sintiéndose las estudiantes que se investigan como invulnerables, no supeditadas ni subordinadas, aunque el racismo se vive en el contexto de la escuela.

Para comprender las dificultades de alcanzar un mejor accionar docente, hay que destacar la inadecuada formación inicial de los docentes que dificulta la adaptación al ritmo de los cambios circulares del país (Guadalupe et. al., 2017). A ello se suma el cambio de la composición demográfica actual de las escuelas, debiendo presenciar casos de segregación escolar sin contar con el conocimiento de estrategias pedagógicas suficientes (Guadalupe et. al., 2017).

En nuestra ponencia "Desigualdad, exclusión y procesos identitarios en los discursos y comportamientos estudiantes en el nivel secundario de la clase media de Lima", señalamos lo siguiente:

Pero no bastará con que el cambio educativo parta de una concepción macropolítica del poder, es necesario descentrar los discursos educativos para comprender el mundo de la vida estudiantil, buscando la transformación más que la reproducción y la norma (De la Vega, 2007) y de ese modo coadyuvar a la desaparición de los cismas que excluyen a ingentes cantidades de ciudadanos y ciudadanas. Precisamente el ideal cívico estudiantil de la ciudadanía no es ajeno a la responsabilidad, entendida como la conciencia que posee el ciudadano sobre cómo repercute su actuar en el espacio público ya que, en la medida en que se formen los estímulos, valores y modelos de referencia educativos en ellos, se conformarán ciudadanos que decidirán con su actividad o pasividad la calidad de los sistemas democráticos futuros y proyectos que vinculen al alumno con la realidad y que lleve a la acción lo que aprende en las aulas, que le permita entender para qué aprende (GascaPliego y Olvera-García, 2011).

Sin embargo, esta tarea se hace muy difícil si consideramos cómo se establece una generalización de lo mixto convirtiéndose la escuela en un espacio juvenil situado con frecuencia en el margen del aprendizaje escolar, es decir, "cada vez más alumnos pasan más tiempo en la escuela; los muros que protegían la institución se han derrumbado" (Dubet, 2007, p. 54). Sumemos a ello, cómo es que la competitividad escolar ha aumentado por el simple hecho de la multiplicación del número de competidores, derivándose dos consecuencias, la formación de un mercado escolar en el seno mismo de la escuela pública, y el desarrollo del utilitarismo de las familias y de los alumnos, que todos condenan pero en el que todos participan (Dubet, 2007). No basta 
con ciertos contenidos educativos basados en valores integradores y positivos desde toda perspectiva ya que una misma narrativa puede ser utilizada por estrategias radicalmente opuestas: los controles y las resistencias pueden enfrentarse utilizando una misma línea discursiva (De la Vega, 2007). Se trata de una labor de descentramiento (Derrida, 1989), ya que los estudiantes reinventan discursos ambivalentes y aparentemente contradictorios que, en la tónica de Derrida, sería una continua deconstrucción en que lo que se propone como marginal para la institución -lo discriminatorio- se convierte en lo central, siendo validado y legitimado como lo "verdadero".

En este contexto el parecer de los escolares permite abrir formas de participación de vital importancia a través de "las opiniones o ideas ya que los niños encarnarán la expectativa de que goce de la escucha y debida atención de los demás; así como ser aceptados en su composición y comentario, atribuyéndosele criterios suficientemente válidos y pertinentes" (Cussiánovich y Bazán, 2009. p. 38). Recuérdese que para promover la ciudadanía de los niños y las niñas, será necesario "romper con el esquema jerarquizante respecto a la niñez, con el adultocentrismo y con todas aquellas representaciones sociales que la reducen a ser súbdita y no actora social" (Cussiánovich, 2007, p. 30). Como establecen García Méndez y Mary Beloff, citado por Valencia (2009):

Los niños pueden encontrar protección en el estado civil, producto del pacto social, pero no forman parte de él. Aquello que para todas las personas excluidas del pacto parece ser una contradicción, para los niños es una situación normal, pero que los excluye del pleno ejercicio de los derechos de ciudadanía. El camino de los derechos que tienen los niños hasta su reconocimiento es más largo que el de los otros sujetos excluidos del pacto social moderno. (Valencia, 2009, p. 67)

Cabe sustentar una posición en defensa de la participación ciudadana infantil partiendo de que todo sujeto es portador tanto de lo universal como de lo particular. La ciudadanía no solo implicará la pertenencia a una comunidad política y el conjunto de derechos y deberes derivados deésta, sino una constante agencia representada en la intensa relación entre individuo y comunidad. Es así que la participación de la infancia es un proceso iniciado en diversos ámbitos: la familia, la escuela, la ciudad y las relaciones con la Administración, en general. Todo ello implica la necesaria y progresiva participación de los niños y niñas en todos los ámbitos, es decir, a la consideración de los niños y niñas como ciudadanos de pleno derecho en nuestra sociedad del siglo XXI (Fernández, 2009). 
Se busca entonces, con la presente investigación, una mirada coadyuvadora de iniciativas que integren al escolar en cuanto al respeto y consideración de su percepción, así como la posibilidad de fomentar su participación activa, tanto en la vigilancia como en la promoción de los componentes alimentario y nutricional (Vásquez, 2012), convirtiéndolo en sujeto de derechos (Leroy, 2009) más que simple objeto de cuidado. Se insta, en este sentido, a concebir un enfoque de consulta con los niños que sea fuente de la producción de políticas públicas. Es por ello vital la construcción de mecanismos que institucionalicen la participación del niño en "todos los niveles de la toma de decisiones relevantes del gobierno, los niños deben estar directamente involucrados en determinar los métodos de participación para garantizar que éstos sean accesibles y amigables para ellos" (Cit. En NATS, 2009, p.11).

\section{RESULTADOS}

Mediante Decreto Supremo № 008-2012-MIDIS se creó el Programa Nacional de Alimentación Escolar Qali Warma como Programa Social del Ministerio de Desarrollo e Inclusión Social. Su objetivo, según se establece en el mismo Decreto, es el de brindar un servicio alimentario de calidad adecuado a los hábitos de consumo locales, para niños y niñas de los niveles de educación inicial y primaria de la educación básica en instituciones educativas públicas. Para lograr sus fines cogestiona con la comunidad, basándose en la corresponsabilidad entre el Estado y la comunidad organizada, considerando actores del sector público en la ejecución de las prestaciones, a fin de garantizar un servicio de calidad, diversificado, descentralizado y sostenible.

La cogestión considera las necesidades y potencialidades de la comunidad, con la intención de promover su desarrollo, la participación ciudadana de la población, la vigilancia y el monitoreo social. Con ello Qali Warma busca ir más allá de la imposición de cómo debe pensar la población escolar infantil o, acaso, considerarlos como meras figuras decorativas que aparenten estrategias de inclusión participativa de las y los niños, que esconden formas de "tokenismo" o formas de manipulación por parte del sector público (Castro, 2009, p.49). La participación escolar se identificó de modo grupal e individual. En cuanto a los grupales incluía a diferentes estudiantes en una tarea común, como lavar los vasos y el balde que contenía la leche, entre otros. Las labores individuales (aunque de buen grado fuera parte de toda la labor colectiva) incluían, por ejemplo, el servir la leche en los vasos o el repartir los mismos a los compañeros y compañeras.

\footnotetext{
31 Alumna del 5togrado B de la institución educativa 83010 de Bambamarca.
} 


\subsection{Motivaciones para la participación efectiva}

Aquello que conlleva a los niños a participar, más allá del modo en que fueron designados, será de nuestro interés en este punto. Si bien podían, para ellos representaba "algo para ayudar, y además es fácil" 31 , otros estudiantes sufren una paradoja en donde la participación tan ansiada, se contrapone a cierto grado de vulnerabilidad que han de sufrir:

Niños: Nos discriminan porque repartimos leche.

Facilitador: Si a ustedes les insultan, les tratan mal, etc., ¿para qué ayudar?

Niños: Porque la profesora nos manda. Porque nosotros queremos ser responsables con nuestro colegio. Nos gusta ayudar a repartir la leche..$^{33}$

Los niños y las niñas no se ven en la obligación de actuar por amor a sus prójimos, ya que éstos no valoran lo que hacen ¿entonces por qué?: o bien son obligados, o bien tienen un designio de responsabilidad difícil de evadir, en especial en los brigadieres $u$ otras autoridades escolares, o bien lo hacen porque les gusta. Cuando los profesores mandan, o mejor dicho, cuando lo encargan, los estudiantes sienten una responsabilidad importante: "Me siento muy bien, porque la profesora me puso en eso, confía en mí y siente que yo le puedo ayudar". ${ }^{33}$ Se reafirma la necesidad de obtener la gracia institucional de mano de los docentes: "Lo hago desde el inicio, el profesor nos llamó y me dijo ayúdame a repartir, ven Alicia, ven, vine y fui y dijo que reparta. Yo quería porque estábamos preparando la ensalada. Me gusta ayudar al profesor, a veces él no puede y yo le ayudo". ${ }^{34}$ Dicha aprobación se manifiesta, inclusive, en emociones y sentimientos mutuos: "Para agradecérmelo me da un abrazo (la profesora) lo has hecho bien me dice". ${ }^{35}$

La confianza de que los niños son objeto son los más importantes aportes para su creciente participación, según se constata, sumado al amor y al cariño del cual son objeto una vez realizada la ayuda hacia sus profesores. La motivación de la responsabilidad será parte del designio que portan consigo diversos estudiantes producto de la confianza que los profesores y las autoridadeseducativas pusieron en ellosy enellas. Elbrigadier dela institución educativa 622 si bien representa el caso más poderosamente participativo de todos gracias a su iniciativa, deja en claro el peso de su cargo y de sus funciones. Para él participar es mucho más que quedar bien con los demás:

Grupo de discusión de la institución educativa 22313 de Ica.

Niño del 5to grado B de la institución educativa 83010 de Bambamarca.

Niña del 6to grado G de la institución educativa Germán Tejada de Moyobamba.

Niña del 6to grado de la institución educativa 622 de Rioja. 
Un mes después de que llegó (el programa) empecé a ayudar a repartir desayunos. Ordeno a los que les toca repartir. Lo hago porque el brigadier tiene que cumplir con sus deberes. Me siento bien porque hago el bien y no hago el mal. (...) Mis padres me dicen que me van a seguir apoyando, los profesores no me dicen nada, y no me molesta, no lo hago para que me den las gracias, sino por mi voluntad. Para mí sí es importante, porque es al dar a las personas, al decirles que no rieguen la leche, para que no falte, sino hacen un desastre y faltaría para los demás, mejor doy órdenes, (en caso de que) sino lo hago yo cuando me toca" 36

El designio funcionaría como un desafío del cual algunos niños son capaces de llevarlo a cabo, aunque los profesores no otorguen agradecimiento alguno:" Lo hago desde que entré al colegio. Siempre lo haré hasta que muera. Me siento bien, ellos se sienten bien porque se alegran y yo me alegro, y entristezco cuando ellos entristecen. Otros no quieren ayudar y yo siempre levanto la mano para ayudar, porque hay un mandamiento que dice que ayudes a tu prójimo y al necesitado." ${ }^{\prime \prime 7}$ Otros lo harán por el mero gusto de hacerlo, en tanto ello les permitirá superar la monotonía, logrando jugar y llevar a cabo una serie de proezas: "Traer los alimentos de alli (señala hacia la dirección) a mi aula, el profesor no puede, porque no tiene tiempo, yo voy porque quiero ir para hacer un poco de ejercicio". ${ }^{38}$. El caminar para un niño puede representar un alivio en tanto debe estar sentado varias horas: “Un día a la semana, si me gusta, hago ejercicio al caminar, desde hace dos días, lo hago todos los lunes" ${ }^{39}$

El gusto por participar contiene su atractivo en la posibilidad de movilizar los cuerpos e interactuar con unos y otros, a lo cual se le suma la noción de hacer algo bueno, algo provechoso para los demás y de lo cual los profesores estarán agradecidos. Tantas bondades en una serie de acciones, resultará una oferta inevitable: "Me animé, es divertido ayudar a mis compañeros y luego nos ponemos a estudiar. Lo hago porque me piden que ayude". ${ }^{40}$ Habrá niños que vean en la posibilidad de colaborar, el poder desempeñar acciones que en el futuro puedan reforzar sus destrezas: "Yo reemplazo porque me gusta la cocina. Siempre lo quiero hacer"41. Incluso son capaces de emular a quienes lo hicieron y con su ejemplo contagiaron a los demás compañeros, en la medida que aquellos terminaron por aburrirse de ir y venir y de tanto ayudar: "Lo

\footnotetext{
Brigadier de la institución educativa 622 de Rioja.

Niño del 6to grado de la institución educativa 22451 de Pisco.

Niño del 5to grado G de la institución educativa Germán Tejada de Moyobamba.

Niña del 6to grado C de la institución educativa 22313 de Ica.

Niño del 5to grado de la institución educativa 622 de Rioja.

Alumna del 6to grado B de la institución educativa Isaac Montalván de Pisco.

Niña del 6to grado A de la institución educativa Isaac Montalván de Pisco.

Alumna del 6to grado A de la institución educativa Virgen del Rosario de Ica.
} 
empecé a hacer) Porque los que recogían me dijeron que les gustaba. Y los que recogían ya no querían y el profesor llamó y yo quise. Ellos estaban aburridos" $"$.

Finalmente, se constata que otros participan para aprovechar los recursos alimenticios al máximo: "Y yo quise, para ayudarles y que no se enfríe al momento en que lo toman"43. Asimismo, buscarán generar el mayor bien posible, ante la posibilidad de que suceda algo malo producto del hambre: "Si es importante porque si no algunos niños se podrían desmayar, mi prima casi se desmaya por no desayunar, más de cinco días" ${ }^{\prime 4}$. Es así que harán lo posible para que todos sus compañeros puedan satisfacerse: "Me gusta porque me gusta el orden y que nadie se quede sin desayuno"45. Son capaces de ser felices con las acciones que emprenden, aunque ello no sea más que un designio, no cesarán de repetir con cierta alegría lo bien que se sienten: Feliz, porque ayudo a los demás a comer ni que sufran cansancio al hacer tarea ${ }^{46}$. Su función es la de llevar a cabo el objetivo final del programa, el de alimentar a los niños: "siento que estoy ayudando y que estoy dando de nutrir a mis compañeros" 47 . Después de todo, con dicha ayuda pueden ampliar sus redes amicales, tratando de agradar a más compañeros, adquiriendo cierto capital simbólico, producto de su importante servicio: "Sí me gusta porque quiero ser solidaria, tener amigos, tengo bastantes amigos"48.

Finalmente, cabe destacar que en este último rubro, las y los niños expresarán su deseo por ayudar a quienes se supone tienen el rol de servirles los desayunos, las madres: "Para que la señora no sufra tanto para llevar a otros salones, para que la señora se encargue de una sola cosa"49. La participación escolar conjugaría dos acciones, la de llevar a cabo una tarea en beneficio de los demás compañeros, y el disminuir el agotamiento de las madres: "creo que es bueno darles leche a cada uno y repartir las galletas, y a las madres que se cansan ayudarles"50. Inclusive se referirán al cuidado en lo que puedan decir de la comida que ellas prepararan: "Que mi compañera decía "Ay no, está fea", y la mamá que había preparado la comida y estaba ahí se sintió mal. No se daba cuenta que le hicieron sentir mal". ${ }^{51}$

\subsection{Problemas suscitados al participar .}

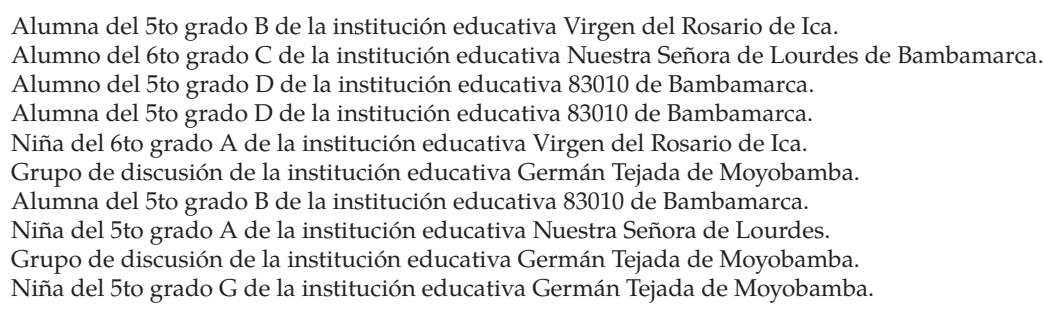


Una dificultad que lleva a las y los niños a poner en tela de juicio su participación, alejándolos de la participación, será el deseo de utilizar su tiempo libre en el juego, en especial en los niños ${ }^{52}$ : "Una vez no lo hice porque no alcé la mano cuando profesor pidió voluntarios, es que estaba jugando (...) antes no (participaba) porque yo jugaba tuti fruti y me distraía, ahora ya no juego porque no quiero distraerme" ${ }^{53} \mathrm{El}$ juego no debe hallarse en el lado opuesto de la participación. Estos casos no son mayoritarios porque los niños y las niñas partícipes en el servicio de los desayunos, ven en sus roles un claro ejercicio lúdico, a pesar de la responsabilidad que requiere. El otro polo del juego y la distracción será el estudio. Justamente el miedo a perder las clases o de no hacer la tarea a tiempo es otra amenaza, ya que al repartir los demás estarán concluyendo algunas tareas. Veamos el modo en que se entrecruzan la diversión y la responsabilidad de las tareas: "Es divertido distraerse a estar sentado. No quiero ayudar en más cosas, porque también tengo que estudiar". ${ }^{54}$

Los que se aventuran podrían perder la posibilidad de mantenerse atentos a algunas indicaciones. Por ello es que algunos profesores preferirán utilizar el número de lista: "Se hace por orden de lista, sí me gusta porque para que haya más tiempo de hacer tarea" 55 . Las niñas, haciendo uso de su responsabilidad reforzada por los mismos niños y sus profesores, tratarán de llevar a cabo sus funciones, en la medida que no perjudiquen sus estudios: "Cuando estoy sentada y dicen que lleve el balde, cuando hago tareas no la oigo y le digo a mi amiga, pero quiero, cuando acabo la tarea si quiero". ${ }^{56}$

Sin embargo, otros niños, en su mayoría hombres, rechazarán su participación porque pone en peligro el cumplimiento de sus tareas y por ende sus calificaciones. Un niño nos indica que la mayoría no querrá a pesar de que los llaman porque "Nos toca hacer la tarea por eso no quieren"57. Otro testimonio rehúye de cualquier tipo de participación ya que asegura, "no me alcanza el tiempo, a veces tengo tarea"58. Inclusive opondrán resistencia: "Sí, a uno le tocó pero estaba haciendo su trabajo, profesora le obligó" ${ }^{59}$. Finalmente, una niña nos menciona que su experiencia participativa no le gustó: "No me gustó, teníamos que venir a clases y estar repartiendo el pan. No quiero perder las clases"60 De esta manera, únicamente un selecto grupo de niños y niñas serán los únicos capaces de no solo saber equilibrar sus funciones participativas con el estudio, sino de terminar a tiempo, antes que el resto de alumnos: “Unos no

\footnotetext{
Niña del 5to grado A de la institución educativa 622 de Rioja.

Alumno del 6to G de la institución educativa Manuel del Águila de Rioja.

Niña del 5to grado B de la institución educativa Germán Tejada de Moyobamba.

Alumno del 5to grado A de la institución educativa 622 de Rioja.

Alumno del $6^{\circ}$ grado B de la institución educativa Santiago Apóstol de Cajamarca.

Alumna del 6to B de la institución educativa Isaac Montalván de Pisco.

Niña del 6to grado B de la institución educativa Santiago Apóstol de Cajamarca.

Niño del 5to grado G de la institución educativa Germán Tejada de Moyobamba.
} 
pueden ayudar porque no terminan de escribir lo que pone el profesor en la pizarra"61. Ello los lleva a pensar que sólo aquellos con capacidades superiores al resto pueden participar en dichas tareas. Se propicia cierto monopolio de la participación que es reforzado por los propios profesores, propiciándose la conformación de una especie de élite en lo participativo: "La profesora también elige responsables, no es solo las que quieren, sino los más responsables, la misma cantidad". ${ }^{62}$ Ello puede reproducir formas de segregación y discriminación autofigurada: "Si, son los niños más inteligentes, más habilidosos y los que más participan". ${ }^{63}$

Este tipo de situaciones puede tener serias consecuencias entre los propios niños, quienes pelearán por captar la atención de los profesores, en busca de obtener un rol importante. Dos importantes testimonios colectivos dan cuenta de los conflictos generados en contextos de una pobre deliberación democrática en torno a quienes deben ser los encargados de las funciones asignadas por las y los profesores:

Si, por quien reparte, pelean. Algunos cuando no les toca a ellos, ellos se pasan, se meten ahí (en los alimentos) esos de ahí van y les tocan y empiezan a discutir. Discuten porque quieren traer la leche. Algunos se molestan porque mis compañeras les traen galletas partidas. Algunos se sienten fastidiados porque no los han escogido. Cuando el profesor manda a traer las galletas algunos quieren ir y otros van. ${ }^{64}$

Otro factor es el miedo que tendrán de servir la leche o incluso de llevar los vasos a manos de sus compañeros, ya que ésta puede caer en el piso, ocasionando en algunos casos el enojo de los profesores: "Hoy al servir, regué en la mesa de mi compañero. Casi me bota, el profesor dijo que pida perdón" 65 . Una niña comenta "yo no quería (participar) porque se derramaba la leche y se enojaban"66. El miedo es patente, debido a su sentimiento de inseguridad, el cual termina por menospreciar sus capacidades.

Habrá casos en los cuales accidentalmente al servir la leche, esta se derramará un tanto, lo que producirá el enojo de algunos, al punto de llevar su protesta al desperdicio de dicha porción láctea: "Algunos dicen "porqué lo derramas" y lo botan"67. El que la leche caiga sería causa del desorden en el mayor de los casos. En efecto, otra de las cosas que más incomoda a los

\footnotetext{
62 Niño del 5to grado A de la institución educativa Nuestra Señora de Lourdes de Bambamarca.

63 Niña del 5to grado B de la institución educativa Isaac Montalván de Pisco.

Grupo de discusión de la institución educativa Germán tejada de Moyobamba.

Alumno del 5to grado B de la institución educativa Nuestra Señora de Lourdes de Bambamarca.

Alumna del 6to grado A de la institución educativa Divino Maestro de Cajamarca.

Grupo de discusión de la institución educativa Germán Tejada de Moyobamba.

Grupo de discusión de la institución educativa Germán Tejada de Moyobamba.
} 
escolares que participan al momento de servir los desayunos será el desorden: "la leche se riega, se pelean"68.

El miedo hacia el desorden solo puede desaparecer ante la presencia de algún profesor. En estos contextos no habrá representante alguno con la legitimidad que pudimos percibir en otras instituciones educativas: "Cuando el desayuno es a la hora de recreo pegan a la que reparte porque no está la profesora. Cuando no está la profesora se vuelven demonios. Empujan o se quitan". ${ }^{69}$ Incuso será debido a que habrá alguien que deseará que aquella persona que se encuentra colaborando, caiga al momento de llevar la leche, sin pensar en el daño que puede ocasionarle. Este tipo de comportamiento se observó en casi todas las instituciones educativas:

Niños: Algunas veces se tropieza. Le insultan. Algunos ponen el pie para tropezar, los más malcriados.

Facilitador: ¿Y por qué?

Niños: Porque algunos tienen envidia. Porque la profesora más nos favorece a nosotros porque sabemos hacer. ${ }^{70}$

Este tipo de violencia tendrá, entre otras motivaciones, lo aludido a la incapacidad de los profesores por saber colmar las expectativas de los niños en desear participar. Si bien el número de orden evita este tipo de competencias violentas, las actitudes belicosas no dejarán de hacer su aparición ocasionando, inclusive, malestar en sus víctimas:

Algunos cuando están repartiendo les molestan, ponen el pie y ahí ponen cabe y caen. Algunos se han raspado la rodilla. Dejan destapado y el mismo le empuja para que caiga. A veces dejan ahí el vaso así abierto y a veces vienen y alguien empuja y se le derraman en el uniforme. Creen que somos molestosos porque solo queremos poner orden. Algunos ponen el pie para caernos. Algunos nos pegan. A veces los insultan porque no les dan dos panes. Insultan diciendo la anoréxica está repartiendo. ${ }^{71}$

Estas actitudes terminan por degenerar en una auténtica violencia, ya sea mediante las palabras o incluso física que cala en lo profundo de sus víctimas, como fue el caso de una niña de una institución educativa en Ica: "Siempre lo haré. Me siento bien porque ayudo a mis compañeros y al profesor. Una vez los niños me querían pegar por repartir la leche. Yo participe sin que me digan. A

\footnotetext{
Grupo de discusión de la institución educativa 22313 de Ica.

Grupo de discusión de la institución educativa 298 de Moyobamba.

Grupo de discusión de la institución educativa Manuel del Águila de Rioja.

Niña del 6to grado C de la institución educativa 22313 Ica.

Niño del 6to grado de la institución educativa Divino Maestro de Cajamarca.
} 
pesar de todo lo que hago, me tratan mal... (empieza a llorar)". ${ }^{72}$ Ello puede llevar a cierta venganza por parte de los agredidos, propiciando un abuso de poder en manos de quienes reparten los desayunos. Uno de ellos recuerda el modo en que se desquitaba de lo poco que le solían servir: "Si, recuerdo que me decían que les servía poco y a mí mucho, si era cierto, me desquitaba porque otros me servían poco, ellos no le decían, se reían nomás"73.

Como última dificultad que se identificó en torno a la participación, se considera que los profesores tienden a tomar, en aquellas instituciones educativas sin una distribución de los poderes representativos escolares, como una mano de obra de inferior calidad y necesaria ante el vacío de quienes deben llevar a cabo las auténticas tareas de servicio de los desayunos, refiriéndonos en este punto a las madres. Una niña comenta "a veces están completas las madres y ya no lo hago"74. Acudimos a una serie de acciones que recortan las capacidades infantiles prohibiéndoles participación alguna en consideración a un tutelaje que los inhibiría: "(Participar es) muy bonito, pero aún no me toca, profesora dice que prefiere que sea la mamá, yo quiero pero mi mamá tiene que $\mathrm{ir}^{\prime \prime} .75$

Ello lleva a los alumnos a sentir que su rol y sus funciones en el servicio de los desayunos se limitaría a facilitar la tarea de los verdaderos encargados en dichos papeles, en una suerte de dependencia. Una entrevista grupal a niños que no habían participado lo suficiente respondían que participar era importante ya que: "hay mucho trabajo para las mamás, para lavar los vasos que están tirados en el comedor" 76 . Es así como los propios niños y niñas disminuirán la importancia de ser ellos quienes lleven el desayuno a sus propias manos o mejor aún, tener un rol más protagónico en la consecución de sus derechos alimenticios: "Este mes empecé, porque el próximo vienen las mamás. Prefiero a las mamás, porque son mayores y tienen tiempo. Nosotros no, porque hay quienes no saben (...) no es que lo hagan mal, a cada salón le toca un turno". ${ }^{77}$

No hay mayor diferencia entre ayudar a los padres, que ayudar a los profesores. Se trata de una consecución de responsabilidades que limita enormemente la iniciativa estudiantil que, como vimos en otras instituciones educativas, permite que los alumnos y alumnas tengan a su cargo responsabilidades que compete su propio desarrollo. Los liderazgos colectivos se pierden al depender de las autoridades adultistas: "Me gusta que la señora reparta, a ella le hace caso, a nosotros no nos hacen caso" 78 . Inclusive

Alumna del 6to grado B de la institución educativa 22313 de Ica.

Niña del 5 to grado A de la institución educativa Virgen del Rosario de Ica.

Grupo de discusión de la institución educativa Santiago Apóstol de Cajamarca.

Niña del 6to grado A de la institución educativa Virgen del Rosario de Ica.

Alumna del 5 to grado B de la institución educativa 622 de Rioja.

Niña del 6to grado A de la institución educativa Virgen del Rosario de Ica. 
los padres de aquellos niños que se animen a participar se reservarán sus felicitaciones, ya que son otros los que deberían cumplir las funciones de servir los desayunos y colocarla en manos de los niños y niñas: "(Mis padres) dicen que está bien, pero dicen que deben ir las mamás, que no deberían hacerlo los niños, deben ser más responsables. Los profesores dicen que está bien, para que no se enfríe la leche." 79

La participación no será efectiva por significar un modo de emprendimiento ciudadano o de empoderamiento protagonista infantil: ello sucederá para evitar que "se enfríe la leche". La participación, así, en boca de los niños se convierte en una "ayuda" que si bien no disminuye su importancia, se limita en casi el $90 \%$ de las veces a una ayuda al profesor o profesora. Estos a su vez ven la participación de las y los niños como mera herramienta de ayuda que alivia su trabajo.

Los niños dirán "mi profesora está cansada" o "está muy cansada", entre otros argumentos que los llevan a asumir responsabilidades que le otorga cierto rol de ayuda de segunda mano de los adultos. Ello no incentiva la participación, por el contrario, la desvirtúa. Leamos el siguiente testimonio: "Lo empecé a hacer porque me llamó mi profesora que estaba cansada, y le ayudé. Me animé porque en mi casa siempre sirvo los desayunos, mi papá o a mi mamá. (...) Mi mamá me dice que ayude a las personas adultas. Si, (es importante ayudar) porque a veces los profes están mal, les duele la cabeza". ${ }^{80}$

En cuanto a aquellos que llevan las bolsas o los baldes de leche o galletas a las aulas, se elegirá, en la mitad de los casos aproximadamente, a los más grandes y a las más grandes, es decir a los niños y niñas más desarrollados. Se fomenta, esta vez, una especie de participación de los niños y niñas que más parezcan adultos. Un adultocentrismo que premia a los niños y niñas que no sólo demuestren ser más "disciplinados y maduros" como los adultos, sino aquellos que han alcanzado una cierta madurez física. El actuar por agradar a sus profesores o a sus padres no tiene por qué ser negativo, en la medida que sea un aliciente y no el contenido mismo de la acción que vienen emprendiendo. Como se analizó, la felicidad y la alegría de ayudar a los demás, lleva a los niños a diversas funciones que van reforzando una identidad participativa muy importante.

Nos dice una niña: "Sí, yo creo que si es importante para que ellos vean que somos de gran ayuda". ${ }^{81}$ Ella insistirá en que los adultos sean capaces de identificar las capacidades de los niños, ya que en aquella institución

Niña del 5to grado A de la institución educativa Nuestra Señora de Lourdes de Bambamarca. 
educativa ya no hay más participación infantil. Otra niña nos demostrará la importancia que tiene confiar en los profesores, sin que ello sea igual a realizar una función en mérito de ellos. Inspira sus pasos al punto de querer seguir haciéndolo siempre: "A mí me gusta ayudar y profesora me dijo "tú me vas a ayudar, yo confío en ti", yo sí quería y de ahí a veces hay alguien para ayudar, yo ayudo. Hasta que acabe la escuela lo haré, si también en secundaria, me gusta ayudar, a mi mamá le ayudo en mi casa". ${ }^{82}$

\subsection{Prejuicios patriarcales}

Una de las dificultades más resaltantes en el aspecto participativo es el prejuicio existente hacia las tareas relacionadas al desayuno. Para muchos niños son actividades reservadas para las mujeres y no para los hombres. Ello se puede identificar a través de las entrevistas y los grupos de discusión. En las primeras las niñas denunciaban como una de las mayores dificultades los comportamientos masculinos que minimizaban la participación femenina; en los segundos se podía apreciar a los propios niños que aceptaban sus prejuicios y trataban de explicarlos, aun a sabiendas de lo equivocados que podían estar. Se trata de discursos difícilmente defendibles en el debate público, pero que son capaces de guiar sus comportamientos.

Una vez identificado dicho fenómeno (debido a los tipos de respuestas iniciales y a la propia mirada etnográfica) se empezó preguntar, a modo de pregunta adicional la participación por género ¿quiénes participan más y por qué? Puede divisarse cierta división del trabajo entre hombres y mujeres. Los hombres se encargarán de asuntos básicos, y las mujeres de las tareas más complejas gracias a su aparente condición innata: "Reparten las galletas y traen. ¿Y las niñas? Sirven las leches. El manjar. El atún. (Los niños más reparten la galleta y traen las niñas hacen lo otro, el atún, el manjar)". ${ }^{83}$ En esta división del trabajo, las niñas son consideradas no sólo más preparadas para tales tareas, sino que se les percibirá como más justas. Sin embargo, las mujeres también sufrirán el prejuicio de su aparente debilidad: "No, porque no me llaman, pero me gustaría, porque me gusta participar en todo. Solo los hombres lo hacen porque son más fuertes, yo me voy al baño a veces a lavarme las manos (motivo por el que no ayuda)" 84

Acudimos a cierto prejuicio que más allá de ser o no compartido por los propios niños y niñas, termina por reforzar ciertos estereotipos de los cuales ni siquiera los escolares podrían estar de acuerdo. Un niño no niega sus deseos

\footnotetext{
83 Grupo de discusión de la institución educativa 298 de Rioja.

84 Niña del 6to grado de la institución educativa 22451 de Pisco.

85 Alumno del 5to grado A de la institución educativa 298 de Rioja.

86 Niña del 6to grado C de la institución educativa 22313 de Ica.
} 
de repartir la leche, una tarea que implica paciencia y tino, características reservadas a las mujeres: Si me gustaría ayudar (además) repartiendo la leche, eso sólo lo hacen las mujeres ${ }^{85}$. Lo peor se dará cuando las niñas no se sientan lo suficientemente bien por el tipo de insultos que reciben, los cuales castigan duramente su participación como un acto deshonroso. La entrevistada estará incomoda por su participación, al punto de decir que a veces resulta negativa: "(Es) malo a veces te dicen sirvienta y, bueno, que está bien que los niños repartan, porque tienen los mismos derechos". ${ }^{86}$

Los niños no sólo se contentarían en participar poco, además harían de cuenta que pagan los servicios de sus compañeras, apurándolas, rebajándolas aún más. Con ello peligraría el nivel participativo alcanzado en algunas instituciones educativas: "Si, (participan) pero pocos (niños). Nos insultan. Apúrate dicen. Te dicen sirvienta, para eso te pago" ${ }^{87}$ En contextos en donde los hombres son la mayoría, el rol cambiará un tanto, empoderándose de ciertas tareas típicamente femeninas en otros contextos escolares. Sin embargo no por ello deja de tener un carácter de género: "Me gusta ayudar, no quiero que les pase nada a mis compañeros, porque la mayoría son mujeres, yo les ayudo a que no se les queme las manos (leche caliente)" 88

Este tipo de prejuicios son reforzados por una mayoría masculina, la cual se reservará tareas que implican esfuerzo. A cambio de ello esperarán que se les sirva, después de todo, no tienen la suficiente paciencia $u$ orden sistemático para hacerlo, según rezan los prejuicios. Nuevamente nos preguntamos ¿y por qué no participan los hombres del mismo modo que las mujeres?: "Porque dicen que las mujeres deben trabajar y los hombres deben estar sentados, que las mujeres deben hacer cosas de la casa, porque los hombres solo se van y traen la leche, pocas veces ayudamos a servir, por que las mujeres son más ordenadas en repartir". ${ }^{89}$ Los aspectos negativos de los niños serán vistos como situaciones comunes que a la larga son aprovechados en su favor. Este tipo de socialización terminará reproduciendo desigualdades injustas que recrudecerían en formas de violencia simbólica. Los niños harán cosas de hombres, y las niñas harán cosas de mujeres: "Los hombres son desordenados y solo les gusta jugar. Les gusta hacer cosas de hombres dicen que eso son cosas para mujeres, cocinar, lavar" ${ }^{\prime \prime 0}$. Veamos como en el siguiente testimonio se citan todos los argumentos hasta ahora mencionados: se autodenominan como "flojos", aceptan no hacer nada y ven en ello un derecho, y tildarán de empleadas a las niñas:

\footnotetext{
Grupo de discusión de la institución educativa 22313 de Ica.

Niño del 5to grado B de la institución educativa 83010 de Bambamarca.

Grupo de discusión de la institución educativa Divino Maestro de Cajamarca.

Grupo de discusión de la institución educativa 83010 de Bambamarca.

Grupo de discusión de la institución educativa Isaac Montalván de Pisco.
} 
Facilitador: ¿Por qué los hombres no ayudan?

Niños: Porque estamos ocupados. Porque son flojos. Porque yo soy hombre no hago nada. Porque eres mi empleada dicen algunos. Otros dicen que eres maricón por lavar. ${ }^{91}$

Inclusive a todo ello le agregaremos la vergüenza que puede recaer en los niños por llevar a cabo acciones típicamente femeninas. Inclusive desde la infancia se propagarán las imprecaciones de tipo homofóbicas. Con ello se puede comprender un tanto más lo negativo que puede resultar para los niños el lavar los vasos y/o el recipiente de leche. Ahondemos en la vergüenza como móvil que degenera en una visión binaria de la sexualidad entre niños y niñas. Según parece, los profesores al saber que los niños no se sienten a gusto, evitarán escogerlos, al menos en algunos contextos en donde la división de la participación resulta muy marcada: "La profesora no los escoge, a los hombres les da vergüenza repartir" "92. Si algunos son obligados a participar, los demás se burlarán de ellos: “Gritan iqué vergüenza!"93. Las niñas convencidas de tal estigma recomendarán que eviten tener ese tipo de vergüenzas, incluyendo a la profesora que evitaría escogerlos. Para ellas es necesario darles una oportunidad, es decir no niegan que deseen participar, aluden cierto monopolio femenino del cual es difícil formar parte a los niños:

Facilitador: ¿Y cómo hacer que los hombres participen?

Niños: Hablándoles con respeto. Diciéndole a la profesora que le dé una oportunidad.

Facilitador: ¿Por qué oportunidad?

Niños: Es que a veces a los hombres no les da. Creo que la profesora no quiere porque son cochinos. Hay que decirle (a los niños) que no es nada malo. Que ayuden y que no tengan vergüenza. Decirles que no es malo repartir. ${ }^{94}$

Como se puede leer en el testimonio, los prejuicios hacia los niños también afectarán sus costumbres higiénicas. Aparentemente tendrán las manos sucias, debido a su propia naturaleza, ya que "por lo general los niños son asi" "95, peor aún, los niños serán "malos" debido a su resistencia a ayudar a los demás ${ }^{96}$. Argumentos de este tipo nos llevan a inferir cierto grado de apropiación femenina por la participación. Nos basamos en la siguiente entrevista grupal:

\footnotetext{
Grupo de discusión de la institución educativa 22313 de Ica.

Grupo de discusión de la institución educativa Santiago Apóstol de Cajamarca.

Grupo de discusión de la institución educativa 22451 de Pisco.

Grupo de discusión de la institución educativa Manuel del Águila de Rioja.

Alumna del 5 to B de la institución educativa 622 de Rioja.

Grupo de discusión de la institución educativa 22451 de Pisco.
} 
Facilitador: ¿Y porque los niños no ayudan?

Niños: Porque estorban. Son más flojos Porque no les gusta ayudar. Dicen que eso lo tienen que hacer las mujeres, no los varones. Dicen que eso lo hacen las mujeres. Facilitador: ¿Y Uds.? ¿Qué dicen?

Niños: Que todos deberían hacerlo

Facilitador: ¿Y qué dice la profesora de eso?

Niños: A los hombres que se portan mal los mandan a servir, en cambio las niñas lo hacen feliz de la vida, y van y ayudan..$^{97}$

Orgullosas de sí, dirán que lo que para ellos es un castigo, para ellas es un privilegio. Más aún, lo único que harían sería estorbar. A estas características que rayan en ciertos argumentos innatos, se suma una suerte de preeminencia lúdica. Los niños estarán dedicados a jugar, por lo cual no tendrán tiempo para participar en labores vinculadas a los desayunos: "Es que los hombres juegan más. Las mujeres participan más porque juegan menos. A sus compañeros no les gustaría hacer lo que ellos hacen porque prefieren jugar". 98 Inclusive, debido al juego constante los niños estarán más sucios, más descuidados. Las niñas conservarán su capital simbólico, aquel que les reserva cierto control sobre sí mismas. Veamos el parecido entre dos grupos de discusión distantes, el primero de ellos en Bambamarca "Porque niñas entienden más de cocina. Porque los niños son niños. Porque niños juegan más y no se lavan las manos. Porque las niñas son hábiles y los niños son descuidados. Los niños no son para esas cosas". ${ }^{99}$ El segundo de ellos en Ica: "Las niñas reparten más porque saben cosas de cocina. Porque los hombres juegan. Las niñas reparten más porque los hombres están jugando. Las niñas son más tranquilas. Las niñas son más responsables que los niños". 100

Puede comprobarse que los adjetivos radicarían en argumentos innatistas que llevan a pensar a las niñas como personas absortas y reflexivas, a diferencia de los niños, que no solo no tienen control sobre sí mismos, sino que son descuidados e irresponsables para con todo lo que les rodea. Los conocimientos en cocina reservados para las niñas, será otro de los argumentos a repetirse constantemente. A la larga se reforzarían los roles de género en las diferentes latitudes geográficas. El siguiente testimonio nos ayuda a entender cómo una niña va percibiéndose a sí misma de aquel modo: "Les gusta repartir, no le ayudan a su mamá, yo sí porque soy mujer y las mujeres siempre reparten. Los hombres también reparten (menos). Me gusta ser

\footnotetext{
Grupo de discusión de la institución educativa Nuestra Señora de Lourdes de Bambamarca.

Grupo de discusión de la institución educativa 83010 de Bambamarca.

Grupo de discusión de la institución educativa 22313 de Ica.

Niña del 5to grado B de la institución educativa 622 de Rioja.

Alumna del 6to grado G de la institución educativa Germán Tejada.
} 
educada, ayudar a las personas que necesitan de apoyo, servir a las personas". ${ }^{101}$

En los testimonios se identificará, inclusive allí donde los niños participan en la preparación, una dedicación a las tareas más sencillas y simples como el preparado de refresco mientras que las niñas prepararán la comida ${ }^{102}$. Ni siquiera podrán sentirse honestos, ya que el rol conservado para los alumnos más justos consistente en repartir el manjar, siempre será reservado para los profesores o para una niña. Los niños no pueden con su voracidad, según se percibe en el imaginario femenino: "los hombres no deben repartir porque pican grueso"103. Ello nos lleva a pensar en que incluso existirá una especie de prejuicio hacia los niños que han de comer más por "naturaleza" y las niñas que, por lo general, comerán menos: "Ellos (los hombres) desayunan más porque son más altos"104. La niña más colaboradora y participativa de la institución educativa 22451 de Pisco, relatará que suele servirles más a los niños que a las niñas. Las que desean pueden incluso repetir en sus vasos, no se les niega; sin embargo, la propia profesora convencerá a sus alumnos de que son los niños los destinados a alimentarse más (y mejor) que las niñas. Tal vez con ello se trate de convencer a los niños que tomen la leche que tanto aborrecen en algunos casos; sin embargo, no se puede evitar correlacionar todos aquellos argumentos en una división de género tan injusta como peligrosa en la socialización de las y los niños:

"A los hombres les sirvo llenecito y a las mujeres por la mitad, para que los hombres tengan más fuerza, casi las mujeres no comemos tanto, los hombres por naturaleza comen más harto. Algunas mujeres lo toman llenecito. Yo no, ya mucho desayuné en casa. La profesora nos enseñaba así (se sabe el nombre de todos) me ayudan dos niños, son los más tranquilos". ${ }^{105}$

\section{CONCLUSIONES}

1. Participar no se puede concebir como un término monolítico, dado que implica diversas dimensiones ya analizadas a lo largo del artículo. Se pudo encontrar que los niños se sienten más identificados con la oportunidad de interactuar con sus compañeros al momento de cumplir sus roles a la hora del desayuno escolar. Interactuar es participar, teniendo un valor muy grande para ellos, así se les obligue, no habrá rastro ni huella de malestar alguno. Lo cumplirán con suma alegría, como ellos y ellas señalaron. Se comprueba que el supuesto servicio mejorado hacia los niños en

\footnotetext{
103 Ídem.

104 Alumna del 6to grado A de la institución educativa Virgen del Rosario de Ica.

105 Niña del 6to grado de la institución educativa 22451 de Pisco.
} 
comedores atendidos por personas contratadas y madres de familia amputa la participación infantil inutilizando sus capacidades organizativas, así como sus potencialidades creativas en pos de empoderarse de los desayunos como un servicio al cual no sólo les corresponde consumir como un derecho, sino a responsabilizarse de la tarea que implica su labor.

2. La participación de los niños y las niñas representan un puente muy importante entre el Estado y el consumo de los alimentos capaz de incrementar su nivel identitario entre lo que consumen y el rol que cumplen para que ello sea posible a través de su vida escolar organizacional. Ello resulta muy difícil de lograrse en contextos institucionales en donde se les concibe como meros objetos para educar y no como agentes prestos a construir formas democráticas participativas en sus propias instituciones educativas. Prueba de ello es la exclusión que existe entre el estudio y la participación, llevando a las y los niños a una disyuntiva que los obliga a elegir. Ello debe ser considerado por los profesores, quienes deben integrar este proceso como uno muy importante en la formación de la personalidad de sus estudiantes y en una sana socialización.

3. El servicio de desayunos detonará dos tipos de conflictos. El primero en torno de quién o quiénes deben cumplir las funciones en torno al servicio del desayuno. Como se explicó a través de los testimonios, los niños operarán con ira y violencia hacia aquellos que reparten los alimentos, provocando que dicha participación se limite a una mera colaboración con sus profesores. El segundo en torno al prejuicio hacia las niñas, o peor aún, hacia los niños quienes se verán a sí mismos impedidos de cumplir una serie de funciones. A través de las entrevistas se pudo explorar que el nivel participativo de las niñas sobrepasaba al de los niños, por ser una labor "de mujeres" según pensaban muchos niños. Las niñas, a su vez, terminaban por incorporar dicha lógica a sus propios juicios.

4. Algunos docentes solo buscan quien les ayude, obnubilando las grandes posibilidades de fomentar responsabilidades en la niñez en la cual desde ya puede verse a personas capaces de proponer y de crear una serie de actitudes ciudadanas en función de sus intereses y el de su contexto. En torno al segundo conflicto, la reproducción de ciertos estereotipos, tanto masculinos como femeninos, minimizarían el papel de las mujeres como responsables de ciertas tareas que a los ojos de los niños no tendrán mayor valor. Éstos a 
su vez recortan sus capacidades y se autodefinen como incapaces de autorrealización alguna, de la mano de una vida dedicada a las actividades lúdicas. Ello no solo menoscaba los intereses y objetivos del programa en cuanto a niños y niñas como partícipes del mismo, sino que estructura formas injustas de violencia simbólica que recrudecerán en el futuro a través de una socialización basada en brechas injustas de género.

5. La participación escolar, como se explicó, tendrá dos vertientes: aquella en la cual los niños se sienten parte del proceso, y aquella en donde son inhibidos, por una supuesta incapacidad de los mismos por llevar a cabo una serie de funciones reservadas para los adultos que en todo momento deben cuidar de ellos. Existirá una posición intermedia en donde encontramos una participación infantil que basa su comportamiento en una emulación de servicio a los profesores, como lo venía haciendo hacia sus padres. Ello no buscaría sino emplearlo como mera herramienta de apoyo al profesor y a su función educativa. En efecto, la hora del desayuno es tan rápida como vacía de contenidos educativos, sin considerar las enormes posibilidades académicas y cívicas que ello contiene detrás de sí. Empoderar a la niñez como protagonistas de los objetivos del programa de alimentación debe ser una búsqueda compartida entre profesores, padres de familia y el Estado.

6. Cabe destacar, finalmente, que los resultados arrojan una clara estrategia organizativa, ya sea en la niñez organizada por el colegio, o en la niñez auto organizada ante la necesidad. La institución educativa debe ser capaz de identificar esta importante agencia infantil capaz de abrirse paso frente a la adversidad, al caos y el desorden. A ello agreguémosle la capacidad que muchos de ellos poseen de racionalizar los alimentos, aprovecharlos y saber repartirlos en beneficio de todos; así como saber administrar los tiempos entre el desayuno, las clases y el recreo. Ello comprueba que si se les da el espacio y la confianza necesaria en sus opiniones y en su participación, ellos y ellas demostrarán capacidades aún mayores, con lo cual la elección participativa de los niños se convertirá en una celebración deliberativa y democrática, evitando así el rol autócrata de los profesores. 


\section{REFERENCIAS}

Carrillo, S. (2017). Actitudes hacia la profesión docente y condiciones de bienestar: ¿una década de cambios y continuidades? Revista Peruana de Investigación Educativa. N. 9. Lima.

Cussiánovich, A. (2007). Los niños y niñas en una sociedad de cómplices. Paeidiatrica $\mathrm{N}^{\circ}$ 9. ISSN 1728-239X Recuperado de: sisbib.unmsm.edu. pe $>$ BVRevistas $>$ Paediatrica $>$ pdf

Cussiánovich, A. y Bazán, M. (2009). La experiencia de la organización propia ¿qué es eso de participar? Lima: Terre des hommes Alemania.

Cuenca, R. (2015). Justicia social, educación y desigualdad. Justicia, derecho y Sociedad, debates interdisciplinarios para el análisis de la justicia en el Perú. Marianella Ledesma (Coord.). Centro de Estudios Constitucionales.

Cuenca, R. (2012). ¿Mejores maestros? Balance de políticas docentes 20102011. Serie de Insumos para el Diálogo 11. USAID.

De la Vega, E. (2007). "Micropolítica institucional y mecánica del poder en la escuela". Cómo prevenir la violencia en la escuela: estudio de casos y orientaciones prácticas. Nolberto Boggino Editor. Rosario: Homo sapiens.

Demarini, F. (2017). En primaria juegas; acá en secundaria, no, transición a secundaria en instituciones educativas públicas de Lima. Revista Peruana de Investigación Educativa. N. 9. Pp 85-111. Recuperado de: http:/ / revistas.siep.org.pe/RPIE/article/view/59

Derrida, J. (1989). La desconstrucción en las fronteras de la filosofía. Paidós.

Dubet, F. (2007). El declive y la mutación de las instituciones. Revista de Antropología Social. No 16. Recuperado de : https://dialnet.unirioja. es / servlet/articulo?codigo $=2499755$

Fernández, J. (2009). Los niños y las niñas: ¿Ciudadanos de hoy o de mañana? Revista Alternativas № 16 . Editorial Universidad de Alicante. Departamento de Trabajo social y Servicios Sociales

Gasca-Pliego y Olvera-García (2011). Construir ciudadanía desde las universidades, responsabilidad social universitaria y desafíos ante el siglo XXI. Convergencia $N^{\circ}$ 56. Revista de Ciencias Sociales, vol. 18, 
núm. 56, mayo-agosto, pp. 37-58. Universidad Autónoma del Estado de México Toluca, México Recuperado de : http:/ /www.redalyc.org/ articulo.oa?id=10516855002

Guadalupe, C.; León, J., Rodríguez, J. y Vargas, S. (2017). El estado de la educación en el Perú, análisis y perspectivas de la educación básica. Grade.

Jacinto, P. (2017). Interculturalidad, identidad y discriminación en la escuela. Justicia e interculturalidad, análisis y pensamiento plural en América y Europa. Marianella Ledesma (Coord.). Centro de Estudios Constitucionales.

Leroy, Aurélie (2009). ¿Contra el trabajo infantil? Supuestos a debatir. NATS $\mathrm{N}^{\circ}$ 17. Año XIII. Agosto. Edit. Diskcopy SAC

Loayza, J. (2011). Juventud y clandestinidad en Lima, imaginarios y prácticas violentas. Fondo Editorial Universidad Nacional Mayor de San Marcos.

Magde, A. (2017). La disputa entre lo justo y lo bueno: construcciones de ciudadanía en Ayacucho. Justicia e interculturalidad, análisis y pensamiento plural en América y Europa. Marianella Ledesma (Coord.). Centro de Estudios Constitucionales.

Ministerio de Inclusión Social - MIDIS (2013). Guía de conformación del Comité de Compras y Comité de Alimentación Escolar. Autor.

Morales, P. (2012). Estadística aplicada a las ciencias sociales. Tamaño necesario de la muestra ¿cuántos sujetos necesitamos? Recuperado de http://www. upcomillas.es/personal/peter/investigación/Tama\%F1oMuestra.pdf

NATS $\mathrm{N}^{\circ} 17$ (2009). A veinte años de la convención sobre los derechos del niño. Autor. Agosto. Edit. Diskcopy SAC.

Nugent, G. (2010). El orden tutelar. Lima, Desco-CLACSO.

Stojnic, L. y Carrillo, S. (2016). Influencia de los años de educación formal y de la calidad educativa en las actitudes democráticas de jóvenes latinoamericanos. Innovación y calidad en educación en América Latina. Santiago Cueto (Editor). GRADE.

UNICEF (2006). Convención sobre los derechos del niño. Autor.

Valencia, Jorge (2009). Participación de los niños y las niñas. IFEJANT. 
Vásquez, C. (2012). La alimentación escolar como oportunidad de aprendizaje infantil. FAO. Disponible en http://www.rlc.fao.org/fileadmin/ templates/fondobrasil/documentos/Alimenta_Esc_Oportun_ Aprend_infantil.pdf

Fecha de recepción: 10 de setiembre de 2019

Fecha de aceptación: 16 de octubre de 2019 